\section{Multiple activities change intervention as a vehicle for changing the mental health narrative and practice}

Atul Agarwal *

"[Psychiatrists] were so committed to a neurobiological model of brain chemistry that socioeconomic factors seemed unscientific." ${ }^{1}$-Ecks, S M, in Eating Drugs: Psychopharmaceutical pluralism in India

"The burden of mental disorders is likely to have been underestimated because of inadequate appreciation of the connectedness between mental illness and other health conditions. Because these interactions are protean, there can be no health without mental health." ${ }^{2}$ - Prince et al, 2007

On 28th July 08 a 33 old male presented with history of stress, worry, and anxiety since childhood, backache since 2002, inadequate sleep, headache and body ache, acidity and abdominal discomfort, and throat discomfort - all from 2002. Results with multiple activities change intervention (MACI): baseline BDI-II score 41, 4 days later 11 , and 19 days later 5 . No psycho-pharmaceuticals were used. No interpretation regarding the symptoms was offered. Unfortunately, this man did not come for follow up. But there were others whom I have followed up for longer periods, and I have reported three such cases of drug resistant depression, who were utterly hopeless but showed a 10.31234/osf.io/tbf9 sharp improvement with MACI. ${ }^{3}$ In common mental illnesses (depression and anxiety, alcohol and tobacco use), such sharp improvements are often observed with MACI. Not so sharp but consistent improvements have been observed in some other instances. As a social tool MACI has the potential to change the discourse

\footnotetext{
* Retired Professor

Nagpur, Central India

Please send your feedback to: nagpor@gmail.com
}

in the field of health-and this is equally true for mental health.

Such outcomes could not be explained by existing theories, so I have come up with a novel theory of activities: Reorientation of activities and self-environment integration..$^{4-8}$ This is a first theory that tries to explain our activities. Very shortly, I will also be sharing the methods of MACI.

\section{A grim narrative of mental health}

During WHO Ministerial Conference on Mental Health in 2005, health ministers of European countries made a declaration: "We endorse the statement that there is no health without mental health [emphasis added]. Mental health is central to the human, social and economic capital of nations and should therefore be considered as an integral and essential part of other public policy areas such as human rights, social care, education and employment."

In 2007, The Lancet published a series of articles on mental health in low-income and middle-income countries. ${ }^{2,10-}$ ${ }^{14}$ This was followed up by another series in 2011. ${ }^{15-20}$ These twelve articles paint a grim narrative of mental health scenario, especially in low and middle-income countries of Asia, Africa, and Latin America. Mental health cannot be seen in isolation, as it is connected to other health conditions $^{2}$, poverty ${ }^{19}$, a broad range of humanitarian settings and disasters ${ }^{20}$, and human rights violations ${ }^{15}$. Mental health problems are a leading cause of health-related disability in children and adolescents and have a long-lasting detrimental effects on them, in view of more years lived with illness-yet the mental health needs of children and adolescents are neglected, especially in poorer countries. ${ }^{18}$

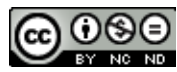 \\ Attribution-NonCommercial-NoDerivs CC BY-NC-ND}

Copyright is with the author. Downloading and sharing of this article is allowed, as long as the author is credited. But changes or commercial uses are not allowed.

This preprint has not been peer reviewed. Author reports no conflict of interest. Date of creation: 19 August, 2020

Suggested citation: Agarwal A. Multiple activities change intervention as a vehicle for changing the mental health narrative and practice [Internet]. PsyArXiv; 2020. Available from: psyarxiv.com/tbfj9 
For many reasons, the burden of mental disorders is likely to have been underestimated. Mental disorders remain untreated or under-treated, constituting what is known as a large treatment gap. One response to this issue has been repeated calls to scale up mental health services. ${ }^{11,16}$ But there are barriers to scaling up, such as the low priority accorded to mental health, scarcity of human and financial resources, and difficulties in changing poorly organized medical care. Not only there is well established and overwhelming worldwide shortage of human resources for mental health, but the current serious shortfall of such resources in countries of low and middle income is likely to grow unless effective steps are taken. ${ }^{17}$ The scarcity of resources for mental health is compounded by inequity of distribution and inefficiency or poor quality; so the populations with high rates of socioeconomic deprivation have the highest need for mental health care, but the lowest access to it. ${ }^{14}$ Another adverse factor is an overconcentration of resources in large institutions based in large cities. ${ }^{21}$ This means that systems for mental health are rarely in place. Innovative approaches are required; and a mental health reform is needed in low and middle income countries, where mental health has a low priority. ${ }^{10}$ But at every level there are unsurmountable barriers to such reforms and innovations, and challenges exist to overcoming them. ${ }^{13}$ Components of mental health at every level of healthcare system needs to be strengthened. But no such scaling up attempt was visible in a recent Indian policy document. ${ }^{22}$ In 2001 at Erwady (a small town in the Ramanathapuram district of Tamil Nadu) 26 mental patients who had been kept chained in a religious asylum were burnt to death. A commission enquiring the tragedy recommended (with other things) setting up of five mental hospitals in the state. The Supreme Court also asked central and state governments to set up in each state at least one hospital that was exclusively for the mentally ill. ${ }^{23}$ (p. 3)

\section{The ground reality throws a grimmer picture}

The picture becomes grimmer when one looks at the ground reality that is characterized by overdependence on psycho-pharmacotherapy and lack of ethics. In an editorial in Indian Journal of Psychiatry, Kallivayalii ${ }^{24}$ was cautiously critical of his peers. "Many times, our treatment might make the patient worse than before. In such instances, increasing the medication or adding a new drug are the options we generally consider. This is often done without carefully listening to the patient, as many of us are extremely busy. We are tempted to believe, drugs are the remedy for all human sorrows and difficulties. We know, a drug which is curative for one may be dangerous for another. Hence, over-reliance on medication can be extremely harmful." Kallivayalil observed that the reason for overdependence on drugs is the neglect that the training and teaching of psychotherapy has faced for long years in India. "Unfortunately, in our country, psychotherapy has been neglected for long. ... There are only few centres in the country which give adequate training and emphasis in psychotherapy even during post-graduate training. This might lead to some of our young psychiatrist colleagues woefully lacking in psychotherapeutic skills."

The actual position may be far gimmer than Kallivayalil's account-as academicians are concerned with exactness and academic commentaries can reveal only a part of the truth. In a recent book Eating Drugs, a variety of narratives that the Indian psychiatrists working in Kolkata used to explain the illness have been described. ${ }^{1}$ Depression was compared with glasses for poor eyesight-to be worn for life (p. 168), with insulin to be taken lifelong (pp. 4, 168), and with food (pp. 188, 197). Ecks called these narratives of clinicians "most folksy explanations for how depression occurs and what the medicines can do". In the first decade of this century, a fierce debate rocked the western psychiatry about a particular group of antidepressants (the selective serotonin reuptake inhibitors or SSRIs) causing higher suicidality among teenage patients. But that barely had an impact in Kolkata (p. 170). Every psychiatrist that was interviewed said that SSRIs were safe for patients, including children and adolescents. Thousands of patients reportedly continued to take lorazepam for years (p. 171). Once a prescription was issued, patients could return to medicine shops over and over for a refill, without doctors having any control over the process. Where the doctor had specified that a course of medicines should be taken for two weeks and that the patient should then return for a check-up, patients could go on with the same prescription for months or even years (p. 176). For psychiatrists, longer maintenance on a lower dose was more lucrative than shorter treatment on a higher dose, and that was why psychiatrists colluded with the pharmaceutical industry to suggest that the bodies and lifestyles of Indian patients were so different that they needed different (smaller) dosages (p. 173). Closely related to lower dosages was the use of polypharmacy (pp. 173-4). "Rubbishing" rival doctors took precedence over evidence-based treatment (p. 177). They (psychiatrists) were so committed to a neurobiological model of brain chemistry that socioeconomic factors seemed unscientific (p. 182).

More than 60 different brands of fluoxetine were available in India in $2008 .{ }^{25}$ This was leading to fierce competition and unethical practices. "Big Pharma" enticed medical practitioners with costly gifts, cash, and even foreign jaunts. Medical representatives visited even unqualified medical practitioners or quacks. To increase the sales, chemists dispensed Schedule-H drugs (to be sold only on prescription of a qualified doctor) even without any written prescriptions. Not content with targeting prescribers, Indian drug companies also tried to change popular notions of depression-disguised as a campaign to raise awareness about the disease. One façade this kind of marketing took was distribution of leaflets that invited people to take a free "self-test" for depression" (p. 151). "Another 


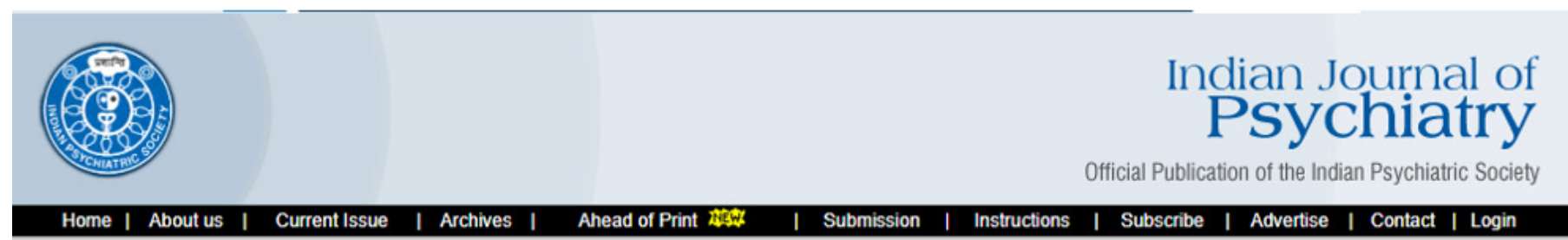

Users online: 1907

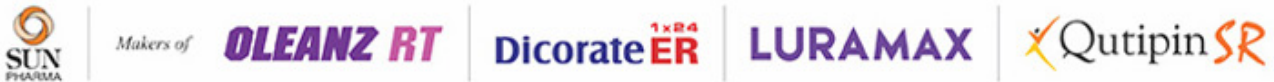

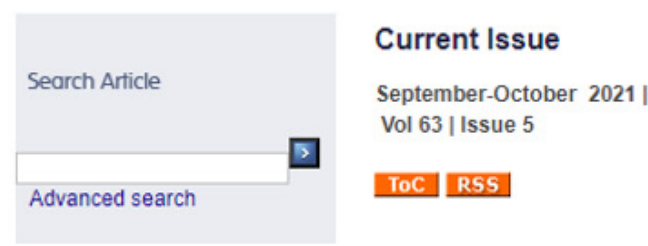

happening is that company representatives are penetrating into patient groups. This has already happened in the West and is probably happening in India. The question asked by such patient groups is, why should patients be denied the latest and most effective treatment just because the drugs are costly?"24

In 2010, American Psychiatric Association issued Practice Guideline for the Treatment of Patients with Major Depressive Disorder. ${ }^{26}$ These guidelines have been criticized for undue emphasis on drug treatment of depression even in mild to moderate cases. The guidelines authors have stated financial conflict of interest, as every APA work group member had commercial ties with companies manufacturing the recommended medications. ${ }^{27}$ Similar emphasis on drug treatment is apparent in Indian guide$\operatorname{lines}^{28}$, in which mentioning any conflict of interest of the authors was not deemed to be necessary. In view of the growing evidence that antidepressants are only marginally better than placebo ${ }^{29}$, during last 12 years, it was not deemed necessary to review these depression guidelines-although separate guidelines for adolescents and elderly came up in the year 2007. In 2014, I observed that the website of Indian Journal of Psychiatry ${ }^{30}$, the official journal of Indian Psychiatric Association, was 'supported' by Sun Pharmaceutical Industries, with hugely prominent display of its products. Sun continues to have a large stake in the Indian market of psycho-pharmaceuticals-and at the time of this writing, Sun Pharmaceuticals continues to prominently advertise its drugs on journal's website, although sponsorship of website by Sun is not clearly mentioned now (see Figure-1).

\section{Is MACI a way out?}

Concerned with Erwadi tragedy, Supreme Court of India and the Commission of Enquiry gave the guidance to the Indian State to set up more and exclusive psychi- atric hospitals (p. 3) ${ }^{23}$ Probably we cannot find fault with the judicial bodies, since they were merely responding to the evidence that was presented to them. The fault must, therefore, lie with those who presented the case of the mentally ill. It shows that even in twenty first century the dominant mind-set was still institutional care for mental illness. Moreover, the dominant mind-set was still in favor of excluding psychiatric services from medical services, as setting up separate hospitals for the mentally ill was explicitly ordered.

More than a decade after Erwadi, something seemed to be changing, as India rolled out its new mental health policy. ${ }^{31,32}$ The document, titled New Pathways New Hopes, National Mental Health Policy of India, identified some of the barriers, documented in the form of research questions: how to integrate mental health with primary healthcare (p. 11), how to identify effective treatments of mental illness (p. 11), and how to implement research so that practitioners use it in a scientific and socially accountable manner (p. 12). The document proceeded to recommend seven directions of strategic action (p. 12), including prevention of mental illness, promotion of mental health, community participation for mental health and development, and improved availability of adequately trained manpower for mental health.

The significance of informal community care and selfcare for mental illness in Indian context has been well recognized. ${ }^{33}$ There is also sufficient evidence to show that specific and focused care can be provided by a wide variety of community resources like the family members, school teachers, volunteers, and the ill persons themselves. ${ }^{33} \mathrm{Ba}$ sicNeeds' approach has shown the links between development, income generation, and recovery from mental illness. ${ }^{34}$ The lesson being learned is that such approaches work and should be multiplied..$^{13}$ Plurality of approaches that have proved to be effective should be enough to break many myths around mental illnesses. ${ }^{35} \mathrm{~A}$ theoretical 


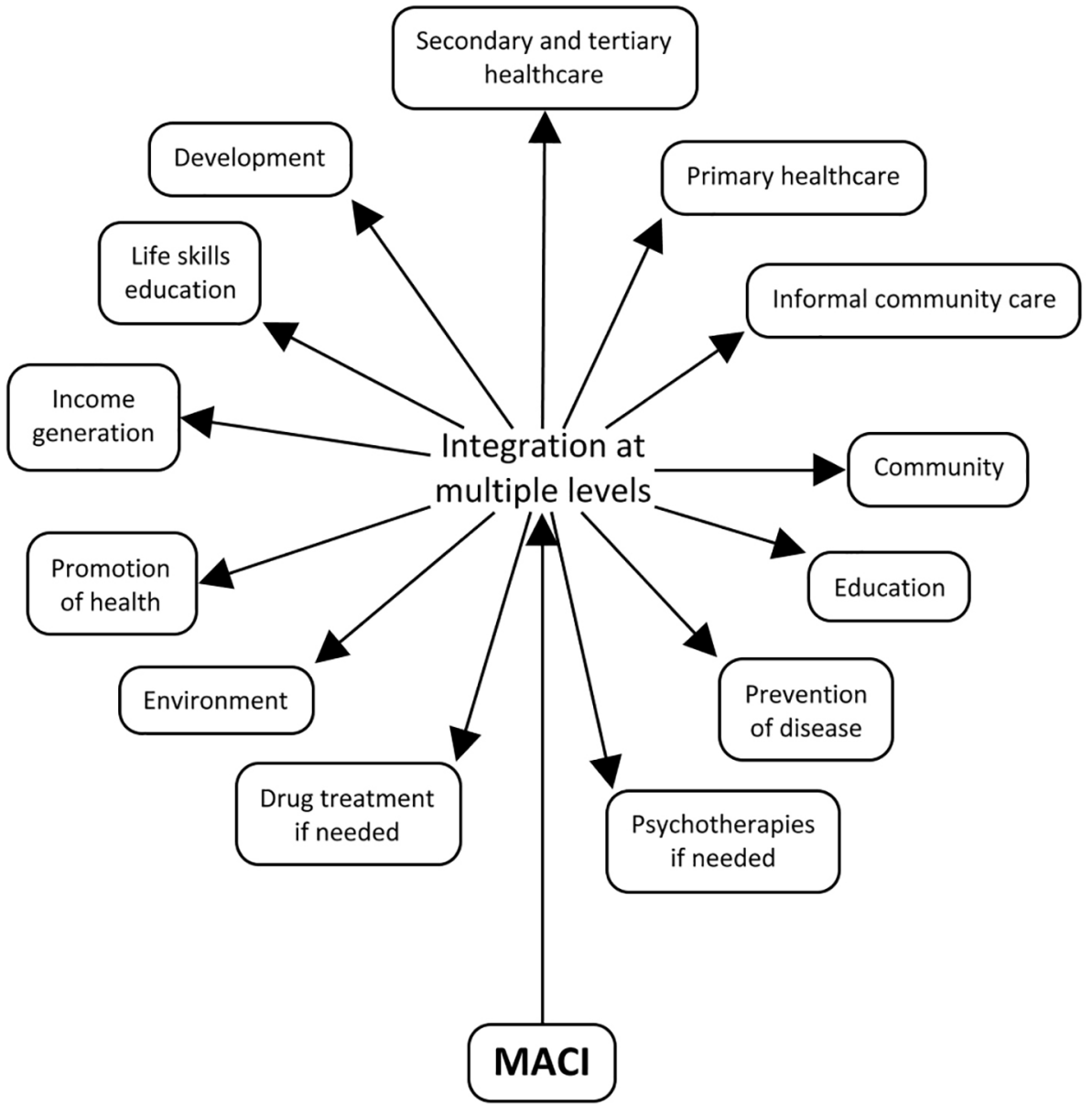

Figure-2. The MACI tree. Some integration levels between MACI (Multiple Activities Change Intervention) and health systems.

framework underpinning these innovative approaches is already in place. ${ }^{36,37}$ Structural changes that affect the whole population have been contrasted with individual biomedical interventions. Community level interventions make more sense and cost less money, and achieve the greatest good of the greatest number. Such an approach is not concerned with the number of disabled people in the population, nor with complex and expensive medical interventions. ${ }^{37}$ Such approaches have been equated with de-medicalization and politicization. ${ }^{36}$ What is happening in the field of mental health seems vastly similar to the occurrences in the field of low-back pain.

I have a compulsive need to place MACI in this perspective. Is MACI a biomedical approach or a community level approach? I will say: it is both. But if I am forced to make a choice, I will be glad to say that it is a community level approach. It fits with the developmental agenda of BasicNeeds. It can be effectively delivered by school teachers, volunteers, health workers, and more. Thus, MACI intervention is not concerned with the number of mentally sick people in the community. It doesn't require any specific pharmacotherapy (such as antidepressants). From medical colleges to primary health centers, the approach of MACI can be learned by physicians, psychiatrists, and health workers-thus making it an ideal tool for integration of mental health services with general health services. MACI is more effective for mental illnesses than any of the other available treatments. MACI will prove to be a good tool for promotion of mental health, prevention of mental illnesses, and community participation in the field of mental health. It will greatly reduce the need for skilled mental health care workers. MACI is in itself a life skill education, as recommended in India's policy document about mental health (p. 13). ${ }^{31}$

Here I have described MACI as a basic community level tool and a tool to integrate mental health with primary health. I will like to emphasize that MACI can also be a sophisticated tool (better than all the other conventional approaches), in the hands of skilled psychiatrists, for the treatment of severe mental illnesses.

MACI can be integrated with health systems at multiple levels (Figure-2) - and at every level it is likely to create an impact. It is highly disruptive tool for overcoming the chaos in mental health that exists today.

\section{References}

1. Ecks SM. Eating Drugs: Psychopharmaceutical Pluralism in India. New York: New York University Press; 2014.

2. Prince M, Patel V, Saxena S, Maj M, Maselko J, Phillips MR, et al. No health without mental health. The Lancet. 2007;370(9590):859-77.

3. Agarwal A. Multiple activities change intervention, a developing psychosocial tool for severe depression: initial report of cases. International Journal of Indian Psychology. 2020;8(2):867-70.

4. Agarwal A. Reorientation of activities and self-environment integration (ROASEI): A new theory of Human 
Activities. PsyXiv 8xz5s [Preprint]. 18 July 2020 [cited 18 July 2020]. Available from: 10.31234/osf.io/8xz5s

5. Agarwal A. Reorientation of activities and self-environment integration (ROASEI)-activities further explained, and theory of activities compared with theories of needs. PsyXiv dxtvh [Preprint]. 13 July 2020 [cited 13 July 2020]. Available from: https://doi.org/10.31234/osf.io/dxtvh

6. Agarwal A. Why do we need a robust theory of activities? PsyXiv fr2uy [Preprint]. 12 July 2020 [cited 12 July 2020]. Available from: https://doi.org/10.31234/osf.io/fr2uy

7. Agarwal A. Reorientation of Activities and Self-environment Integration (ROASEI): Further development and comparison with trait personality theories. PsyXiv 5mcfn [Preprint]. 1 August, 2020 [cited 1 August, 2020]. Available from: https://doi.org/10.31234/osf.io/5mcfn

8. Agarwal A. Perspectives on targeting cardio-vascular diseases through reorientation of activities. PsyXiv $3 \mathrm{mc} 8 \mathrm{~b}$ [Preprint]. 12 July 2020 [cited 12 July 2020]. Available from: DOI: https://doi.org/10.31234/osf.io/3mc8b

9. WHO. Mental health: facing the challenges, building solutions. Report from the WHO European Ministerial Conference. Copenhagen, Denmark: : WHO Regional Office for Europe; 2005

10. Jacob KS, Sharan P, Mirza I, Garrido-Cumbrera M, Seedat S, Mari JJ, et al. Mental health systems in countries: where are we now? The Lancet. 2007;370(9592):1061-77.

11. Lancet Global Mental Health Group. Scale up services for mental disorders: a call for action. The Lancet. 2007;370(9594):1241-52.

12. Patel V, Araya R, Chatterjee S, Chisholm D, Cohen A, De Silva M, et al. Treatment and prevention of mental disorders in low-income and middle-income countries. The Lancet. 2007;370(9591):991-1005.

13. Saraceno B, van Ommeren M, Batniji R, Cohen A, Gureje O, Mahoney J, et al. Barriers to improvement of mental health services in low-income and middle-income countries. The Lancet. 2007;370(9593):1164-74.

14. Saxena S, Thornicroft G, Knapp M, Whiteford H. Resources for mental health: scarcity, inequity, and inefficiency. The Lancet. 2007;370(9590):878-89.

15. Drew N, Funk M, Tang S, Lamichhane J, Chávez E, Katontoka S, et al. Human rights violations of people with mental and psychosocial disabilities: an unresolved global crisis. The Lancet. 2011;378(9803):1664-75.

16. Eaton J, McCay L, Semrau M, Chatterjee S, Baingana F, Araya R, et al. Scale up of services for mental health in low-income and middle-income countries. The Lancet. 2011;378(9802):1592-603.

17. Kakuma R, Minas H, van Ginneken N, Dal Poz MR, Desiraju K, Morris JE, et al. Human resources for mental health care: current situation and strategies for action. The Lancet. 2011;378(9803):1654-63.

18. Kieling C, Baker-Henningham H, Belfer M, Conti G, Ertem I, Omigbodun O, et al. Child and adolescent mental health worldwide: evidence for action. The Lancet. 2011;378(9801):1515-25.

19. Lund C, De Silva M, Plagerson S, Cooper S, Chisholm D, Das J, et al. Poverty and mental disorders: break- ing the cycle in low-income and middle-income countries. Lancet. 2011;378(9801):1502-14.

20. Tol WA, Barbui C, Galappatti A, Silove D, Betancourt TS, Souza R, et al. Mental health and psychosocial support in humanitarian settings: linking practice and research. Lancet. 2011;378(9802):1581-91.

21. Raja S, Wood SK, de Menil V, Mannarath SC. Mapping mental health finances in Ghana, Uganda, Sri Lanka, India and Lao PDR. International journal of mental health systems. 2010;4:11.

22. High Level Expert Group Report on Universal Health Coverage for India. New Delhi: Planning Commission of India; 2011.

23. Agarwal SP, Goel DS, Ichhupuiani RL, Salhan RN, Shrivastava S, editors. Mental Health: An Indian Perspective 1946-2003. New Delhi: Directorate General of Health Services, Ministry of Health and Family Welfare, Government of India; 2004.

24. Kallivayalil RA. Are we over-dependent on pharmacotherapy? Indian J Psychiatry. 2008;50(1):7-9.

25. Ecks S, Basu S. The unlicensed lives of antidepressants in India: generic drugs, unqualified practitioners, and floating prescriptions. Transcultural psychiatry. 2009;46(1):86-106.

26. American Psychiatric Association: Practice Guideline for the Treatment of Patients with Major Depressive Disorder. 3 ed. Arlington: American Psychiatric Association; 2010.

27. Cosgrove L, Shaughnessy AF, Wheeler EE, Austad KE, Kirsch I, Bursztajn HJ. The American Psychiatric Association's guideline for major depressive disorder: a commentary. Psychotherapy and psychosomatics. 2012;81(3):186-8.

28. IPS Guideline Committee on Depression. Clinical Practice Guidelines for the Management of Depression. Indian Psychiatric Society; 2005.

29. Pigott HE, Leventhal AM, Alter GS, Boren JJ. Efficacy and effectiveness of antidepressants: current status of research. Psychotherapy and psychosomatics. 2010;79(5):267-79.

30. Indian Journal of Psychiatry: Official Publication of the Indian Psychiatric Society [Available from: http://www.indianjpsychiatry.org/.

31. New Pathways New Hopes: National Mental Health Policy of India. New Delhi: Ministry of Health \& Family Welfare, Government of India; 2014.

32. Sharma DC. India's new policy aims to close gaps in mental health care. The Lancet. 2014;384(9954):1564.

33. Murthy RS. Mental Health Programme in the 11th Five Year Plan. Indian J Med Res. 2007;125(6):707-11.

34. Underhill C. Mental health and development: from the local to the global. The involvement of mentally ill people in the development process. Asia Pac Disab Rehabil J. 2002;2:1-15.

35. Patel V, Thara R. Meeting the Mental Health Needs of Developing Countries: NGO Innovations in India New Delhi: SAGE Publications; 2003.

36. Oliver M. Disability, politics and health. Critical Public Health. 1995;6(2):2-3.

37. Shakespeare T. Re-defining the disability problem. Critical Public Health. 1995;6(2):4-9. 